Fisioter Bras 2019;20(5);592-3

https://doi.org/10.33233/fb.v20i5.3272

\title{
EDITORIAL \\ O distanciamento do Olimpo: conhecimento ou informação na formação?
}

Prof. Dr. Fernando Zikan

Faculdade de Medicina - Curso de Fisioterapia - UFRJ

fernandozikan@hucff.ufrj.br

Na mitologia grega, o monte Olimpo é a morada dos deuses. Centro da sabedoria e do poder; morada do conhecimento diverso e complementar, representado por seus deuses. A permanência de seu poderio se dava pelo distanciamento aos reles mortais; incultos, obedientes aos seus comandos e facilmente doutrinados.

A disseminação do saber fez com que os deuses, outrora imortais, se aproximassem dos mortais e com isso seu poder foi posto em prova, tornando assim menor a distância ao monte Olimpo.

Ao longo do tempo a busca pelo conhecimento determinou as relações de poder, nas quais este determinava as divisões de classe e a perpetuação do dominador sobre o dominado.

Atualmente a velocidade dos avanços científicos é tão grande que os produtos de conhecimento são traduzidos por fontes de informações. Estas, numerosas e acessíveis a todos, pois não requerem pensamento crítico para obtê-las, produzem uma massa informada, mas desprovida de conhecimento.

A formação em Fisioterapia, no século XXI, teve um crescimento exponencial: tanto pela busca de conhecimento científico quanto pela capacidade de disseminação de informações. Mas e a formação?

Formar melhor é produzir conhecimento ou maior divulgação de informações a um maior número de indivíduos?

Comparando 15 anos de evolução, de 2004 a 2019, o crescimento de cursos de Fisioterapia na América Latina teve formas distintas entre os países. Os países com maior número de cursos em funcionamento eram em 2004: Brasil (298), Colômbia (25), Argentina (15) e Chile (13), os demais não ultrapassavam cinco cursos. Em 15 anos, entretanto, o crescimento se deu da seguinte forma: Brasil (908), Chile (95), Argentina (47) e Colômbia (42), os demais não passaram de 17. Nos dados de 2019 incluímos o México com oferta de 51 cursos.

Analisando os dados tivemos um crescimento na oferta de cursos de $630 \%$ no Chile, $213 \%$ na Argentina, $204 \%$ no Brasil e $68 \%$ na Colômbia, países com maior oferta na América Latina.

Outro dado que chama a atenção é relação entre a oferta por instituições privadas e públicas, sendo: Brasil (dos 908, 854 são privados - 94\%), Chile (dos 95, 77 são privados - $81 \%$ ), México (dos 51, 50 são privados - 98\%), Argentina (dos 47, 31 são privados - 66\%) e Colômbia (dos 42, 35 são privados - 83\%).

No Brasil, o Ministério da Educação utiliza indicadores de avaliação dos cursos de graduação entre eles destaca-se o índice Conceito do Curso e o ENADE (Exame Nacional de Avaliação do Desempenho de Estudantes).

Nos dados de Conceito de Curso de 2019, temos avaliados 644 cursos, dos 908 ofertados (nem todos os cursos foram avaliados devido ao tempo de oferta). Dos 644 cursos, 602 tem notas 4 ou 3 em uma escala que vai de 1 a 5 pontos. Apenas 37 cursos (5,7\%) do total obtiveram nota 5 , destes 09 são de instituições públicas (26,5\% das públicas) e 28 de privadas (4,6\% das privadas).

Resumindo, no conceito do curso (2019), 5,7\% dos cursos avaliados tem nota 5 e 49,7\% dos cursos avaliados tem nota 4 , sendo que $82,4 \%$ dos públicos tem nota 4 ou 5 e apenas $54 \%$ dos privados.

No ENADE (2016), tivemos no último exame de 2016, alunos egressos de 463 cursos que foram avaliados. Também em uma escala de 1 a 5 pontos, $45,8 \%$ do total de cursos tiveram nota 3 , apenas $6,7 \%$ tiveram nota $5 ; 74,1 \%$ dos cursos tiveram notas 3 e 4 , sendo que $72,4 \%$ dos cursos públicos tiveram notas 4 ou 5 e apenas $29,6 \%$ dos privados. 
Neste panorama ainda temos cenários diferentes de atuação docente onde nas instituições públicas os docentes fazem concurso específico para suas áreas de atuação e atuam em ensino, pesquisa e extensão; fato que raramente é realizado nas instituições privadas, no que se refere à produção de conhecimento. Nas instituições privadas ainda o docente é responsável por mais de uma disciplina e nem sempre com especialização e experiência na área de conhecimento.

A Fisioterapia, como ciência, avançou muito nos últimos anos em número de publicações em revistas de alto impacto, no número de profissionais titulados e no número de cursos de pósgraduação strictu senso. Mas observamos que essa produção científica não tem impactado na melhora da formação e do conhecimento adquirido na graduação.

Será que os pesquisadores, pensadores do Olimpo, se distanciaram demais da massa? Como impactar nesse número tão crescente de profissionais se graduando pela América Latina?

Será que pesquisadores brasileiros estão preocupados em solucionar as questões de nosso país com as características e recursos que temos?

Será que com o esforço em se manter revistas e publicações nacionais estamos publicando conhecimento para nossa população de profissionais, que muitos nem o hábito de ler têm, quem dirá em revistas internacionais e em outras línguas?

O mito da caixa de Pandora, voltando à mitologia grega, quer significar que ao homem imprudente são atribuídos os males humanos como consequência da sua falta de conhecimento. Também é curioso observar como o homem depende de sua própria inteligência para não ficar nas mãos do destino, das intempéries e dos próprios humanos.

Estamos abrindo a caixa de Pandora da formação em Fisioterapia? Estamos sendo imprudentes no processo de formação profissional?

Através de um "clique", um "download", nosso "password" nos levará onde?

\section{Referências}

1. Burkert W. Greek religion: archaic and classical. Oxford: Blackwell; 2002. p.205-6.

2. http://siteclafk.wix.com/clafk, accessed 2 Jun 2019.

3. http://emec.mec.gov.br/, accessed 13 Aug 2019.

4. http://download.inep.gov.br/educacao superior/enade/relatorio sintese/2016/fisioterapi a.pdf, accessed 13 Aug 2019.

5. Hsee CK, Ruan B. The Pandora effect: the power and peril of curiosity. Psychol Sci 2016;27(5):659-66. 